\section{Utility of handgrip strength cut-offs for identification of weakness and disability in community-dwelling older people with mild cognitive impairment and Alzheimer's disease}

Utilidade de pontos de corte de força de preensão palmar para identificar fraqueza e incapacidade em idosos da comunidade com transtorno cognitivo leve e doença de Alzheimer

Ivan Abdalla Teixeira'
https://orcid.org/0000-0003-0011-0034

Felipe de Oliveira Silva

https://orcid.org/0000-0002-1457-0480

José Vinícius Alves Ferreira'

https://orcid.org/0000-0002-5025-7483

Jéssica Plácido?

https://orcid.org/0000-0003-1921-6672

Valeska Marinho'

https://orcid.org/0000-0003-4665-9655

Andrea Camaz Deslandes

https://orcid.org/0000-0001-5941-9111

\section{ABSTRACT}

Objectives: To evaluate the utility of handgrip strength cut-offs for the identification of weakness and Instrumental Activities of Daily Living (IADL) disability in elderly people with neurocognitive disorders. Methods: Cross-sectional study of community-dwelling elderly individuals with Alzheimer's disease ( $A D, n=40)$ and mild cognitive impairment $(M C l, n=22)$; healthy individuals ( $n=36$ ) were recruited as controls. Handgrip cut-offs included European Working Group for Sarcopenic Older People (EWGSOP2), Cardiovascular Healthy Study (CHS) and the Frailty in Brazilian Older People Study from Rio de Janeiro (FIBRA RJ) cut-offs. Handgrip strength indexes were calculated by dividing handgrip strength values by cut-off values and the weakness prevalence for each cut-off value was compared among groups. Correlation analyses were employed to evaluate the relationship between Lawton Scale and handgrip strength (crude value and indexes). Results: All handgrip strength indexes were lower in the AD group ( $<<0.05)$, whereas the prevalence of weakness was significantly higher in the AD group only when the CHS cut-off was applied (AD = 47.5\%, MCl and control $=18.2 \%, \mathrm{p}<0.01$ ). Significantly positive correlations were identified between the Lawton ADL scale and handgrip indexes for all cut-offs ( $p<0.05$ ), but not between Lawton scale and crude handgrip ( $p=0.75)$. Conclusions: Only the CHS cut-off allowed proper differentiation of the weakness prevalence between groups. In addition, adjusting handgrip strength values according to cut-offs was necessary to determine the correlation between strength and disability in cognitively impaired elderly individuals.

1 Universidade Federal do Rio de Janeiro, Institute of Psychiatry, Rio de Janeiro, RJ, Brazil.

Address for correspondence: Andrea Camaz Deslandes

Sylvio da Rocha Pollis St. 300, house 02

22793-395 - Rio de Janeiro, RJ, Brazil

Telephone: +55 (21) 97269-7778

E-mail: adeslandes@ipub.ufrj.br 


\section{RESUMO}

Objetivos: Avaliar a utilidade de pontos de corte (PC) de força de preensão palmar (FPP) para identificar fraqueza e incapacidade em atividades instrumentais de vida diária (AIVDs) em idosos com transtorno neurocognitivo. Métodos: Neste estudo de corte transversal, foram recrutados idosos saudáveis $(n=36)$, com comprometimento cognitivo leve (CCL, $n=$ 22) e doença de Alzheimer (DA, $n=40)$. Os PCs incluídos foram o European Working Group for Sarcopenic Older People (EWGSOP2), o Cardiovascular Healthy Study (CHS) e o Frailty in Brazilian Older People Study do Rio de Janeiro (FIBRA RJ). Índices de FPP foram calculados dividindo-se o valor da FPP pelos valores de PC, e a prevalência de fraqueza para cada PC foi comparada entre os grupos. Análises de correlação foram empregadas para avaliar a relação entre a escala de Lawton e a FPP (valores brutos e índices). Resultados: Todos os índices de FPP foram menores no grupo DA ( $p<0,05)$, enquanto a prevalência de fraqueza foi significativamente maior na DA apenas quando o PC do CHS foi aplicado (DA $=47,5 \%$, CCL e controles $=18,2 \%$, $p<0,01)$. Foi identificada uma correlação significativa positiva entre a escala de Lawton e índices com todos os PCs $(p<0,05)$, porém não entre escala de Lawton e valor bruto da FPP $(p=0,75)$. Conclusões: Apenas o PC do CHS permitiu diferenciação apropriada na prevalência de fraqueza entre os grupos. Além disso, o ajuste da FPP de acordo com os PCs foi necessário para determinar a correlação entre força e incapacidade em AIVDs em indivíduos idosos com comprometimento cognitivo.

\section{INTRODUCTION}

Alzheimer's disease (AD) represents a major cause of disability, loss of autonomy and increased dependence in the elderly population'. Frailty and sarcopenia are both more prevalent among AD patients ${ }^{2,3}$ and are associated with negative outcomes, including the incidence of falls, deterioration of mobility, physical disability, poor quality of life, hospitalization and death ${ }^{4-6}$. In clinical settings, detection of sarcopenia and frailty is a challenge ${ }^{7,8}$, but weakness, measured by handgrip strength, is easier to asses and overlaps both concepts ${ }^{4,5}$. The most recent consensus update by the European Work Group for Sarcopenic Older People (EWGSOP2) highlights the importance of handgrip strength in diagnosing sarcopenia ${ }^{8}$ as low handgrip strength is also a clinical marker of poor mobility and a better predictor of clinical outcomes than low muscle mass 9 . There is also a linear relationship between baseline handgrip strength and the incidence of disability in activities associated with daily living (ADL) $)^{10,11}$ and with premature mortality ${ }^{12}$. Measurement of handgrip strength is simple, quick and inexpensive method, that can be considered as an ecological proxy for both frailty ${ }^{7}$ and sarcopenia ${ }^{9}$ in primary care.

Handgrip strength is influenced by sociodemographic and lifestyle factors ${ }^{13}$ and cut-offs based on large epidemiological studies are needed to identify muscle weakness at the level of the individual. Different handgrip strength cut-off values have been proposed based on frailty and sarcopenia models. While the Cardiovascular Health Study (CHS) established cut-offs according to the $20^{\text {th }}$ percentile of strength for each body mass index (BMI) quartile for both sexes in the general population ${ }^{4}$, EWGSOP2 recommendations focus on European populations and the use of normative references (healthy young adults) with cut-offs usually set at -2 standard deviations compared to the mean reference value ${ }^{8,14}$. Handgrip strength is also dependent on the integrity of the central nervous system ${ }^{15}$, as suggested by cross-sectional and longitudinal studies that indicated an association between handgrip strength and cognitive decline ${ }^{16-19}$. However, these studies did not take into account handgrip strength cut-offs to define weakness, using raw handgrip measure $\mathrm{s}^{20-22}$ and comparing cognition between weaker and stronger groups defined by handgrip strength percentile $20,23,24$ or standard deviations of handgrip strength values for that specific population ${ }^{25}$. Despite credible evidence for the correlation of handgrip strength with both cognition $^{18,26}$ and functionality ${ }^{27}$, it is crucial to understand the influence of existing cut-offs in patients with cognitive impairment to enable accurate utilization of handgrip strength measurement as a predictor of disability in a clinical context.

Like sarcopenia and frailty, a higher prevalence of weakness in $A D$ patients was expected when analyzing handgrip strength using different cut-offs. Also, as sarcopenia is associated with $A D L$ impairment in $A D^{6}$, it is supposed that handgrip strength correlates with disability in cognitively impaired individuals. Adjusting handgrip strength according to cut-off values, which corrects for potential bias, may more accurately reflect the correlation with ADL performance than that provided by the raw measures. Therefore, the objective of this study was to evaluate (1) the ability of handgrip strength 
cut-off values to more accurately identify higher weakness prevalence in community-dwelling older people with cognitive impairment; (2) the correlation of handgrip strength with ADL performance in this population; and (3) the ability of handgrip strength measurements adjusted by cut-off values to provide a more accurate reflection of the association with disability than that provided by the raw values.

\section{METHODS}

\section{Study design and participants}

This is a cross-sectional study of community-dwelling elderly individuals with diagnosis of Mild Cognitive Impairment $(M C l, n=22)$ or mild to moderate $A D(n=40)$ from the Center of Alzheimer's Disease of the Psychiatry Institute in the Federal University of Rio de Janeiro (Brazil). Cognitively healthy elderly from community were also recruited as controls $(n=36)$. Diagnostic assessments were performed by clinical staff, using a structured clinical interview to assess mental disorders according to the Diagnostic and Statistical Manual of Mental Disorders (DSM-IV) ${ }^{28}$ and Petersen criteria ${ }^{29}$ for dementia and $\mathrm{MCl}$, respectively. Exclusion criteria included: illiterate; functional classes III and IV according to the New York Heart Association standards; with mental or physical comorbidities that impaired performance during the tests; severe visual and/ or auditory impairments; mixed dementia, with evidence of cerebrovascular infarction in neuroimage; and other comorbid psychiatric disorders, as depression.

Among 41 healthy volunteers, four subjects did not return for evaluation and one was excluded for depression. In the $\mathrm{MCl}$ group, two subjects did not return for evaluation, leaving 22 participants. In the AD group, from initial 61 subjects, ten did not return and others were excluded for: advanced dementia, CDR $3(n=6)$, cardiac disease $(n=2)$, comorbid depression $(n=1)$, inability to perform handgrip $(n=1)$ and mixed dementia $(n=1)$.

This study was approved by the Research Ethics Committee (CAAE) of the Psychiatry Institute in the Federal University of Rio de Janeiro (IPUB-UFRJ), under the registry: 24904814.0.0000.5263 and formed part of a larger research project entitled "Efficacy of physical exercise in the Treatment of Major Depression, Alzheimer's Disease and Parkinson's Disease".

\section{Procedures and measures}

After presenting the details of the study, written informed consent was obtained for all participants. Medication use, physical comorbidities, such as hypertension, diabetes, dyslipidemia, and coronary artery disease, were asked to subjects and their caregivers during anamnesis. ADL performance was assessed through Lawton scale ${ }^{30}$ and global cognition was evaluated applying Mini-Mental Statement Exam (MMSE) ${ }^{31,32}$, Verbal Fluency ${ }^{33}$ and Clock Drawing Test ${ }^{34}$. Clinical Dementia Rating (CDR) scale ${ }^{35,36}$ was applied to measure the severity of dementia in patients with AD.

Handgrip strength was measured using a digital hand dynamometer (Camry", model EH 101), with a variation of 0.1 $\mathrm{kgf}$, ranging from 0 up to $90 \mathrm{kgf}$. Subjects remained standing on the floor, with shoulder adducted, the elbow extended, the forearm in a neutral position, and the wrist extended between $0^{\circ}$ and $30^{\circ}$ extension. Measurement was performed for both hands, and patients were instructed to grip the dynamometer with maximum strength in response to a voice command. This procedure was repeated three times, with a one-minute rest interval between tests. The highest mean peak value between both hands was then recorded for analysis.

According to the handgrip strength cut-off values proposed by the CHS and the EWGSOP2, patients were classified as "strong" or "weak". Both handgrip strength cutoff values were chosen for their roles in the most replicated model for physical frailty and sarcopenia, respectively. With the aim of determining handgrip strength cut-off values based on the local population, we also adopted cut-off values suggested by the Frailty in Brazilian Older People Study from Rio de Janeiro (FIBRA RJ) ${ }^{37}$. All cut-offs are shown in table 1.

To facilitate comparisons among different cut-off values, an index was calculated by dividing the raw handgrip strength value by the corresponding cut-off value for each patient.

Table 1. Handgrip Cut-offs proposed by EWSOP2 consensus and CHS and FIBRA RJ studies

\begin{tabular}{|c|c|c|c|c|c|}
\hline & EWGSOP2 & CHS & & FIBRA & \\
\hline \multirow[t]{4}{*}{ Male } & \multirow{4}{*}{27} & $\mathrm{BMI} \leq 24$ & $\leq 29$ & $\mathrm{BMI} \leq 23$ & $<17.33$ \\
\hline & & BMI 24.1-26 & $\leq 30$ & BMI 23-28 & $<24.93$ \\
\hline & & BMI 26.1-28 & $\leq 30$ & BMI 28.1-30 & $<28.27$ \\
\hline & & $\mathrm{BMI}>28$ & $\leq 32$ & $\mathrm{BMI}>30$ & $<18$ \\
\hline \multirow[t]{4}{*}{ Female } & \multirow{4}{*}{16} & $B M I \leq 23$ & $\leq 17$ & $B M I \leq 23$ & $<12.87$ \\
\hline & & BMI 23.1-26 & $\leq 17.3$ & BMI 23-28 & $<14.27$ \\
\hline & & BMI 26.1-29 & $\leq 18$ & BMI 28.1-30 & $<10.53$ \\
\hline & & BMI > 29 & $\leq 21$ & $\mathrm{BMI}>30$ & $<16.4$ \\
\hline
\end{tabular}

Note -EWGSOP2: European Work Group for Sarcopenic Older People 2; CHS: Cardiovascular Health Study; FIBRA RJ: Frailty in Brazilian Older People Study from Rio de Janeiro. BMl: Body Mass index, $\mathrm{kg} / \mathrm{m}^{2}$. Handgrip, Kgf.

\section{Statistical analyses}

Descriptive analysis of the demographic data was conducted. To verify normality and homoscedasticity, KolmogorovSmirnovand Levenewere applied, respectively. Demographic characteristics, neuropsychological variables, Lawton scale, and handgrip indexes were compared among groups using ANOVA or Kruskal-Wallis test. Bonferroni and Tamhane's T2 post hoc analyses were performed to parametric and nonparametric variables, respectively. For assessing differences among weakness prevalence in healthy, $\mathrm{MCl}$, and $A D$ groups, chi-squared test was used. Correlation analyses were 
employed to evaluate the relationship between Lawton scale and handgrip strength (crude value and indexes). All statistical analyses were performed using SPSS ${ }^{\circ}$ version 19.0 and STATA ${ }^{\circ}$ version 11.0. $\mathrm{p} \leq 0.05$ was considered to indicate statistical significance.

\section{RESULTS}

Descriptive analysis is showed in table 2. There were no significant differences among groups for age and BMI. As expected, cognitive tests and functionality were significantly lower in AD group, compared to $\mathrm{MCl}$ and healthy controls. AD patients used more medication, although comorbidity prevalence was similar for hypertension, diabetes and stable coronary artery disease among groups. Dyslipidemia was more prevalent in the AD group and scholarship was also significantly lower among AD patients.
Handgrip indexes were statistically lower in the AD group for all cut-off values. However, post hoc analyzes only showed significantly difference between $A D$ and healthy subjects for CHS and EWSOP2 handgrip indexes. There was no difference in raw handgrip strength among groups.

Comparison of weakness prevalence among groups is shown in figure 1. There was a significantly higher weakness prevalence in AD group (47.5\%), compared to healthy and $\mathrm{MCl}$ groups (18.2\%) when CHS cut-off was applied $\left(X^{2}=9.38\right)$. However, there was no significant difference for weakness prevalence among groups when EWGSOP2 and FIBRA RJ cut-off were applied.

Correlation between handgrip strength and Lawton scale in cognitively impaired individuals ( $\mathrm{MCl}$ and $\mathrm{AD}$ ) are showed in figure 2. Significantly positive correlations were identified between the Lawton scale and handgrip indexes for all cut-offs, but not between Lawton scale and crude handgrip.

Table 2. Demographic, clinical, functional, cognitive, and strength characteristics by groups

\begin{tabular}{|c|c|c|c|c|c|}
\hline & Healthy $(n=36)$ & $M C I(n=22)$ & $\mathrm{AD}(\mathrm{n}=40)$ & $F / X^{2}$ (p value) & Post Hoc \\
\hline Age $(y)^{\mathrm{a}}$ & $74.5(8.5)$ & $75.6(6.0)$ & $78.0(7.9)$ & $1.97(0.145)$ & - \\
\hline \multicolumn{6}{|l|}{ Sex } \\
\hline Male (\%) & 16.7 & 36.4 & 47.5 & & \\
\hline Female (\%) & 83.3 & 63.2 & 52.5 & $8.15(0.01)^{*}$ & - \\
\hline \multicolumn{6}{|l|}{ Marital Status (\%) } \\
\hline Single & 19.4 & 22.7 & 7.5 & & \\
\hline Married & 44.4 & 36.4 & 50 & & \\
\hline Divorced & 13.9 & 18.2 & 7.5 & & \\
\hline Widower & 22.2 & 22.7 & 35 & $6.18(0.402)$ & - \\
\hline Scholarship (y) ${ }^{b}$ & $12(7)$ & $12(6)$ & $9(7)$ & $10.40(<0.01)^{* *}$ & $A D x H^{*} ; A D x M C I^{*}$ \\
\hline BMI $\left(\mathrm{kg} / \mathrm{m}^{2}\right) \mathrm{b}$ & $25.14(3.20)$ & $25.60(5.84)$ & $25.21(4.91)$ & $1.19(0.550)$ & - \\
\hline \multicolumn{6}{|l|}{ Comorbidities (\%) } \\
\hline Hypertension & 38.9 & 50 & 55 & $2.01(0.365)$ & \\
\hline Diabetes & 5.6 & 9.1 & 20 & $3.94(0.139)$ & \\
\hline Dyslipidemia & 13.9 & 31.8 & 42.5 & $7.51(0.023)^{*}$ & - \\
\hline Coronaropathy & 2.8 & 13.6 & 7.5 & $2.44(0.295)$ & \\
\hline Medications (n) ${ }^{b}$ & $2(2)$ & $2.5(4)$ & $4(5)$ & $13.16(<0.01)^{* *}$ & $A D x H^{* *}$ \\
\hline Lawton (score) ${ }^{b}$ & $21(1)$ & $20.5(1)$ & $13(5)$ & $73.13(<0.01)^{* *}$ & $A D \times H^{* *} ; A D x M C C^{* *}$ \\
\hline MMSE (score) ${ }^{b}$ & $29(3)$ & $29(1)$ & $21(6)$ & $61.25(<0.01)^{* *}$ & $A D \times H^{* *} ; A D x M C l^{* *}$ \\
\hline VF (score) $)^{b}$ & $18(10)$ & $17(7)$ & $9(5)$ & $36.02(<0.01)^{* *}$ & $\mathrm{ADxH}^{* *} ; \mathrm{ADxMCl}{ }^{* *}$ \\
\hline CDT (score) ${ }^{b}$ & $3(0)$ & $2.5(1)$ & $1(2)$ & $35.38(<0.01)^{* *}$ & $\mathrm{ADxH}^{* *} ; \mathrm{ADxMCl} \mathrm{I}^{* *}$ \\
\hline $\mathrm{HS}(\mathrm{kgf})^{b}$ & $23.3(8.8)$ & $24.2(8.2)$ & $23.5(10.5)$ & $1.38(0.501)$ & - \\
\hline EWGSOP2 $2^{\mathrm{b}}$ index & $1.41(0.42)$ & $1.37(0.29)$ & $1.14(0.34)$ & $11.33(<0.01)^{* *}$ & $\mathrm{ADxH}^{* *}$ \\
\hline CHSb index & $1.27(0.32)$ & $1.23(0.30)$ & $1.02(0.37)$ & $9.20(0.01)^{*}$ & $A D x H^{*}$ \\
\hline FIBRA RJ ${ }^{\mathrm{b}}$ index & $1.62(0.44)$ & $1.58(0.42)$ & $1.37(0.45)$ & $6.07(0.048)^{*}$ & $p=0.054$ \\
\hline
\end{tabular}

Note - H: Healthy; MCI: Mild Cognitive Impairment; AD: Alzheimer's dementia; BMI: body mass index; MMSE: Mini-Mental State Exam; VF: Verbal Fluency; CDT: Clock Drawing Test; HS: Handgrip Strength. a Parametric variables: mean (std

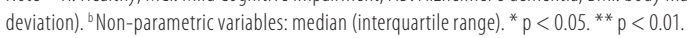

\section{EWGSOP2}

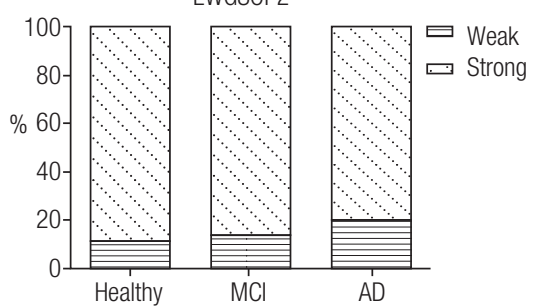

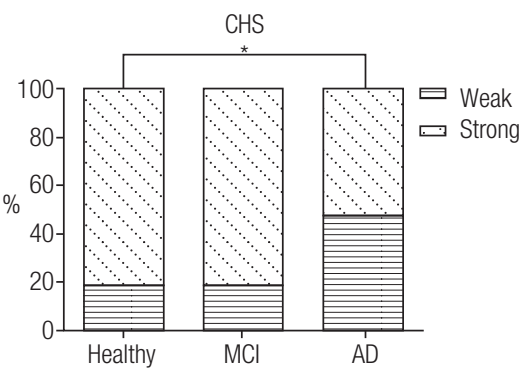

FIBRA RJ

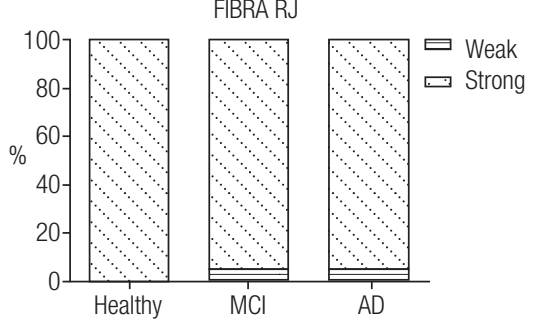

Figure 1. Comparison of weakness prevalence among Groups, According to Different Handgrip Cut-offs. ${ }^{*} p<0.01$. 

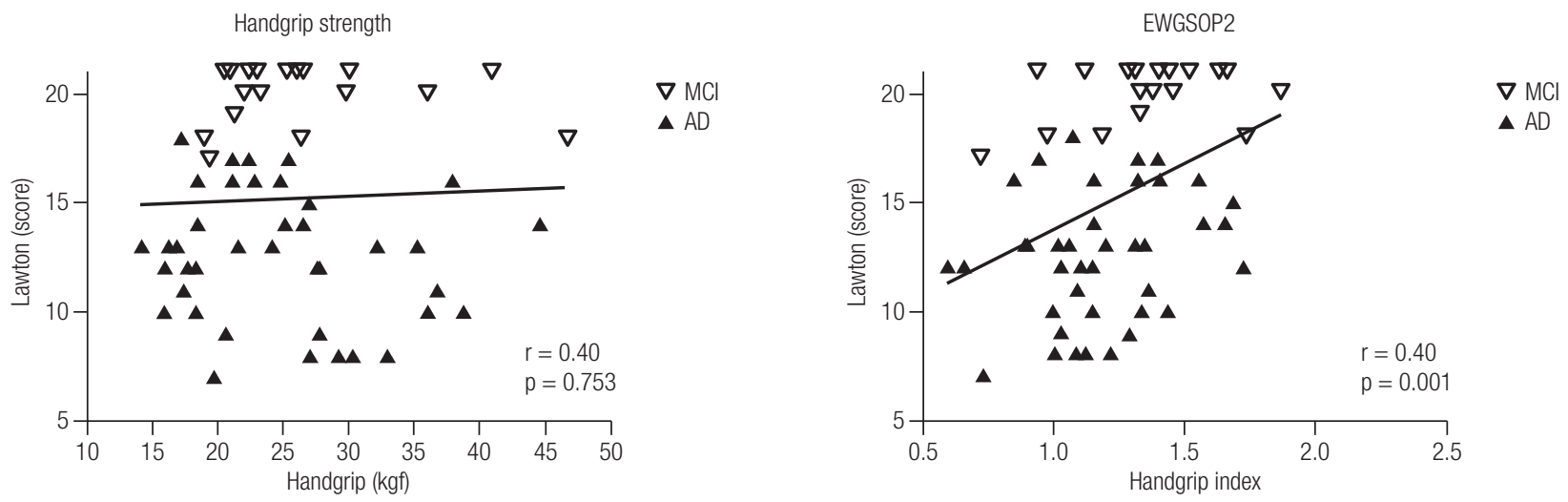

CHS

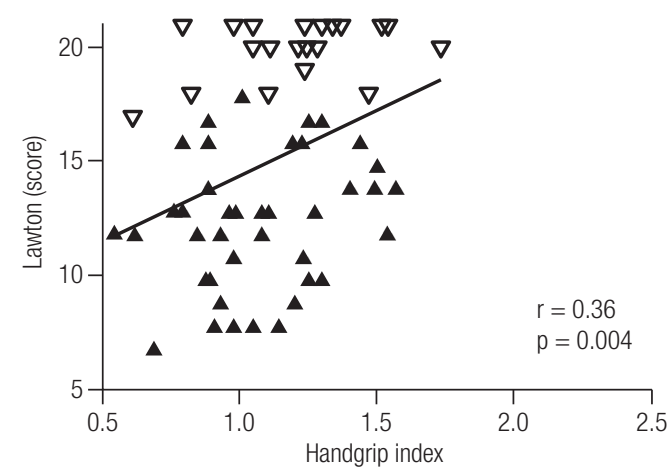

FIBRA RJ

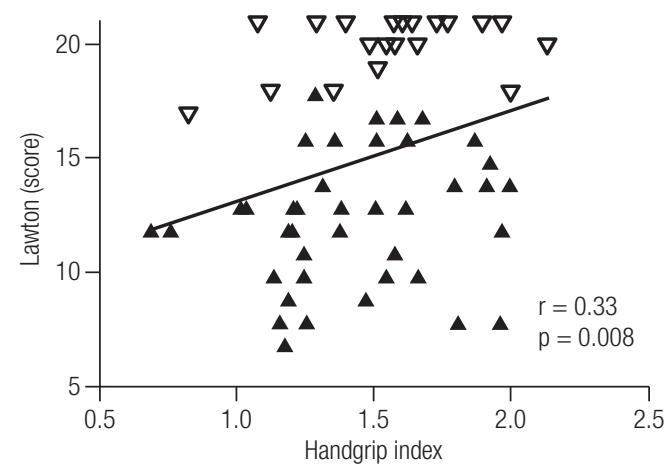

$\boldsymbol{\nabla} \mathrm{MCl}$

$\Delta A D$

Figure 2. Correlation Between Lawton scale and Handgrip Strength (Raw and Indexes Values) in Mild Cognitive Impairment (MCl) and Alzheimer Disease (AD) patients.

\section{DISCUSSION}

In the present study, we evaluated the potential of handgrip strength cut-off values for the identification of weakness and disability in elderly individuals with neurocognitive disorders. Only the CHS cut-off allowed determination weakness prevalence between groups and adjusting handgrip strength by cut-offs was necessary to determine a correlation between

strength and disability in cognitively impaired elderly. The CHS cut-off value revealed a significantly lower handgrip strength index and higher weakness prevalence in the $A D$ group, thus corroborating its applicability for detecting weakness in individuals with dementia. The prevalence of weakness in AD assessed using the CHS cut-off (47.5\%) was consistent with the reported prevalence of sarcopenia (41\%$47 \%)^{38}$, and frailty $(15.7-48.5 \%)^{2}$. These results suggest that $\mathrm{BMI}$ is an important factor in defining handgrip strength cutoff values when evaluating the weakness of patients with cognitive impairment, since CHS stratifies cut-offs by BMI, whereas EWSOP2 does not. Although the FIBRA RJ also adjusts handgrip by BMI and sex, cut-off values are lower than the CHS criteria, resulting in misclassification of patients as "strong".

By calculating handgrip strength indexes, handgrip strength values were adjusted for cut-offs and, consecutively, for sex (EWGSOP2) or sex and BMI (CHS and FIBRA RJ). Handgrip strength indexes facilitated the comparison of cut-off values using a common metric while retaining the ability to analyze strength as a continuous variable, thus allowing quantification of the strength or weakness of individual patients according to different cut-offs. The positive correlation between handgrip strength indexes and ADL performance was observed using all three studied cut-offs, although this correlation was stronger when CHS or EWSGOP2 values were applied. Graphical representation of the distribution of $\mathrm{MCl}$ and $\mathrm{AD}$ revealed the same tendency in both groups. Although the correlation is considered low, it indicates that strength still plays a role in the ADL performance equation even when cognition is impaired. These results suggest that handgrip strength may also represent an opportune target for the preservation of function in cognitively compromised patients. Furthermore, our results provide the foundation for future interventional studies focusing on improving or maintaining function by increasing strength in $\mathrm{MCl}$ and $\mathrm{AD}$ patients. Raw handgrip strength did not correlate with ADL performance, suggesting that sex and BMI are important factors for correcting distortions of absolute handgrip strength measurements in patients with cognitive impairment. This highlights the 
importance of considering cut-offs when studying the relationship between handgrip strength and ADL function.

\section{Limitations}

A cause-effect relationship between strength and functionality cannot be established using a cross-sectional design. Diagnostic components of frailty and sarcopenia were not evaluated, precluding direct comparisons between weakness prevalence and frailty or sarcopenia prevalence. The possibility of direct interference of cognition during the testing process is important issue that should be considered when analyzing strength in AD patients. Due to potential cognitive effects on the measurements, patients with advanced dementia were excluded; therefore, our analysis was focused on patients in the mild and moderate stages. This approach is in accordance with reports showing that handgrip strength is a reliable measure until the moderate stages of cognitive impairment are reached ${ }^{39}$.

\section{Implications}

To our knowledge, this is the first study to show that handgrip strength cut-offs are useful for detecting weakness and correlating handgrip to $\mathrm{ADL}$ performance in communitydwelling older people with cognitive impairment. These data highlight the relevance of handgrip strength as an additional measure of cognitive decline in the clinical setting. The differences in the handgrip strength cut-off values demonstrated in this study are crucial for guidance in dementia care facilities, where relevant cut-off values are required for interpretation of handgrip strength on individual patient basis.

\section{CONCLUSIONS}

Handgrip cut-offs are useful for identifying weakness and correlating strength to disability among communitydwelling elderly patients with cognitive impairment in a clinical setting, although the CHS cut-off is superior for identifying weakness prevalence in mild-to-moderate AD.

\section{INDIVIDUAL CONTRIBUTIONS}

All authors substantially contributed to conception, design, analysis and interpretation of data, substantially contributed to drafting the article and revising it critically for important intellectual content; and have given the final approval of the version to be published.

\section{CONFLICT OF INTERESTS}

The authors declare that there is no conflict of interest.

\section{ACKNOWLEDGMENTS}

This work was supported by the Conselho Nacional de Desenvolvimento Científico e Tecnológico under Grant (CNPq301483/2016-7); and the Fundação Carlos Chagas Filho de Amparo à Pesquisa do Estado do Rio de Janeiro under Grant (Faperj-E-26/203.193/2016) and (Faperj- E-26/203.160/2016). This study was submitted to the Brazilian Registry of Clinical Trials (ReBEC) under the RBR-4M3K2C identification: http:// apps.who.int/trialsearch/Trial2.aspx?TrialID=RBR-4m3k2c.

\section{REFERENCES}

1. Alzheimer's Association. 2016 Alzheimer's disease facts and figures. Alzheimers Dement. 2016;12(4):459-509.

2. Kojima $G$, Liljas A, lliffe S, Walters K. Prevalence of frailty in mild to moderate alzheimer's disease: a systematic review and meta-analysis. Curr Alzheimer Res. 2017;14(12):1256-63.

3. Sugimoto T, Ono R, Murata S, Saji N, Matsui Y, Niida S, et al. Prevalence and associated factors of sarcopenia in elderly subjects with amnestic mild cognitive impairment or Alzheimer disease. Curr Alzheimer Res. 2016;13(6):718-26.

4. Fried LP, Tangen CM, Walston J, Newman AB, Hirsch C, Gottdiener J, et al. Frailty in older adults: evidence for a phenotype. J Gerontol A Biol Sci Med Sci. 2001;56(3):M146-56.

5. Cruz-Jentoft AJ, Baeyens JP, Bauer JM, Boirie Y, Cederholm T, Landi F, et al. Sarcopenia: European consensus on definition and diagnosis: Report of the European Working Group on Sarcopenia in Older People. Age Ageing. 2010;39(4):412-23.

6. Sugimoto T, Ono R, Murata S, Saji N, Matsui Y, Niida S, et al. Sarcopenia is Associated With Impairment of Activities of Daily Living in Japanese Patients With Early-Stage Alzheimer Disease. Alzheimer Dis Assoc Disord. 2017;31(3):256-8.

7. Lee L, Patel T, Costa A, Bryce E, Hillier LM, Slonim K, et al. Screening for frailty in primary care: accuracy of gait speed and hand-grip strength. Can Fam Physician. 2017;63(1):e51-7.

8. Cruz-Jentoft AJ, Bahat G, Bauer J, Boirie Y, Bruyere 0, Cederholm T, et al. Sarcopenia: revised European consensus on definition and diagnosis. Age Ageing. 2019;48(1):16-31.

9. Lauretani F, Russo CR, Bandinelli S, Bartali B, Cavazzini C, Di lorio A, et al. Age-associated changes in skeletal muscles and their effect on mobility: an operational diagnosis of sarcopenia. J Appl Physiol. 2003;95(5):1851-60.

10. Al Snih S, Markides KS, Ottenbacher KJ, Raji MA. Hand grip strength and incident ADL disability in elderly Mexican Americans over a seven-year period. Aging Clin Exp Res. 2004;16(6):481-6.

11. Henriksson $H$, Henriksson P, Tynelius P, Ortega FB. Muscular weakness in adolescence is associated with disability 30 years later: a population-based cohort study of 1.2 million men. Br J Sports Med. 2019;53(19):1221-30.

12. Ortega FB, Silventoinen K, Tynelius P, Rasmussen F. Muscular strength in male adolescents and premature death: cohort study of one million participants. BMJ. 2012;345:e7279.

13. de Lima TR, Silva DAS, de Castro JAC, Christofaro DGD. Handgrip strength and associated sociodemographic and lifestyle factors: A systematic review of the adult population. J Bodyw Mov Ther. 2017;21(2):401-13.

14. Dodds RM, Syddall HE, Cooper R, Benzeval M, Deary IJ, Dennison EM, et al. Grip strength across the life course: normative data from twelve British studies. PLoS One. 2014;9(12):e113637

15. Christensen H, Mackinnon AJ, Korten A, Jorm AF. The "common cause hypothesis" of cognitive aging: evidence for not only a common factor but also specific associations of age with vision and grip strength in a cross-sectional analysis. Psychol Aging. 2001;16(4):588-99.

16. Rijk JM, Roos PR, Deckx L, van den Akker M, Buntinx F. Prognostic value of handgrip strength in people aged 60 years and older: a systematic review and meta-analysis. Geriatr Gerontol Int. 2016;16(1):5-20.

17. Fritz NE, McCarthy CJ, Adamo DE. Handgrip strength as a means of monitoring progression of cognitive decline - A scoping review. Ageing Res Rev. 2017;35:112-23. 
18. Kobayashi-Cuya KE, Sakurai R, Suzuki H, Ogawa S, Takebayashi T, Fujiwara Y. Observational Evidence of the Association Between Handgrip Strength, Hand Dexterity, and Cognitive Performance in Community-Dwelling Older Adults: A Systematic Review. J Epidemiol. 2018;28(9):373-81.

19. Praetorius Björk M, Johansson B, Hassing LB. I forgot when I lost my grip-strong associations between cognition and grip strength in level of performance and change across time in relation to impending death. Neurobiol Aging. 2016;38:68-72.

20. Alfaro-Acha A, Al Snih S, Raji MA, Kuo YF, Markides KS, Ottenbacher KJ. Handgrip strength and cognitive decline in older Mexican Americans. J Gerontol A Biol Sci Med Sci. 2006;61(8):859-65.

21. Auyeung TW, Kwok T, Lee J, Leung PC, Leung J, Woo J. Functional decline in cognitive impairment - the relationship between physical and cognitive function. Neuroepidemiology. 2008:31(3):167-73.

22. Huang CY, Hwang AC, Liu LK, Lee WJ, Chen LY, Peng LN, et al. Association of Dynapenia, Sarcopenia, and Cognitive Impairment Among Community-Dwelling Older Taiwanese. Rejuvenation Res. 2016;19(1):71-8.

23. Jang JY, Kim J. Association between handgrip strength and cognitive impairment in elderly Koreans: a population-based cross-sectional study. J Phys Ther Sci. 2015;27(12):3911-5.

24. Taekema DG, Gussekloo J, Maier AB, Westendorp RGJ, de Craen AJM. Handgrip strength as a predictor of functional, psychological and social health. A prospective population-based study among the oldest old. Age Ageing. 2010;39(3):331-7.

25. Jeong S, Kim J. Prospective Association of Handgrip Strength with Risk of New-Onset Cognitive Dysfunction in Korean Adults: A 6-Year National Cohort Study. Tohoku J Exp Med. 2018;244(2):83-91.

26. Zammit AR, Robitaille A, Piccinin A, Muniz-Terrera G, Hofer SM. Associations between aging-related changes in grip strength and cognitive function in older adults: A systematic review. J Gerontol A Biol Sci Med Sci. 2019;74(4):519-27.

27. Gopinath B, Kifley A, Liew G, Mitchell P. Handgrip strength and its association with functional independence, depressive symptoms and quality of life in older adults. Maturitas. 2017;106:92-4
28. American Psychiatric Association. Diagnostic and Statistical Manual of Mental Disorders. 4th ed. Washington, DC: American Psychiatric Association; 2000.

29. Winblad B, Palmer K, Kivipelto M, Jelic V, Fratiglioni L, Wahlund LO, et al. Mild cognitive impairment - beyond controversies, towards a consensus: report of the International Working Group on Mild Cognitive Impairment. J Intern Med. 2004;256(3):240-6.

30. Lawton MP, Brody EM. Assessment of older people: self-maintaining and instrumental activities of daily living. Gerontologist. 1969;9(3):179-86.

31. Folstein MF, Folstein SE, McHugh PR. "Mini-mental state". A practical method for grading the cognitive state of patients for the clinician. J Psychiatr Res. 1975;12(3):189-98.

32. Bertolucci PH, Brucki SM, Campacci SR, Juliano Y. [The Mini-Mental State Examination in a general population: impact of educational status]. Arq Neuropsiquiatr. 1994;52(1):1-7.

33. Brucki SM, Malheiros SM, Okamoto IH, Bertolucci PH. [Normative data on the verbal fluency test in the animal category in our milieu]. Arq Neuropsiquiatr. 1997;55(1):56-61.

34. Fuzikawa C, Lima-Costa MF, Uchoa E, Barreto SM, Shulman K. A population based study on the intra and inter-rater reliability of the clock drawing test in Brazil: the Bambuí Health and Ageing Study. Int J Geriatr Psychiatry. 2003;18(5):450-6.

35. Hughes CP, Berg L, Danziger WL, Coben LA, Martin RL. A new clinical scale for the staging of dementia. Br J Psychiatry. 1982;140:566-72

36. Montano MBMM, Ramos LR. [Validity of the Portuguese version of Clinical Dementia Rating]. Rev Saude Publica. 2005;39(6):912-7.

37. Moreira VG, Lourenco RA. Prevalence and factors associated with frailty in an older population from the city of Rio de Janeiro, Brazil: the FIBRA-RJ Study. Clinics (Sao Paulo). 2013;68(7):979-85.

38. Ogawa Y, Kaneko Y, Sato T, Shimizu S, Kanetaka H, Hanyu H. Sarcopenia and Muscle Functions at Various Stages of Alzheimer Disease. Front Neurol. 2018;9:710.

39. Alencar MA, Dias JMD, Figueiredo LC, Dias RC. Handgrip strength in elderly with dementia: study of reliability. Rev Bras Fisioter. 2012;16(6):510-4. 